Voix et Images

voixetimages

\title{
Bibliographie de Louise Dupré
}

\section{Mélanie Beauchemin et Nathalie Watteyne}

Volume 34, numéro 2 (101), hiver 2009

Louise Dupré

URI : https://id.erudit.org/iderudit/029469ar

DOI : https://doi.org/10.7202/029469ar

Aller au sommaire du numéro

Éditeur(s)

Université du Québec à Montréal

ISSN

0318-9201 (imprimé)

1705-933X (numérique)

Découvrir la revue

Citer ce document

Beauchemin, M. \& Watteyne, N. (2009). Bibliographie de Louise Dupré. Voix et Images, 34(2), 97-118. https://doi.org/10.7202/029469ar d'utilisation que vous pouvez consulter en ligne.

https://apropos.erudit.org/fr/usagers/politique-dutilisation/ 


\title{
B I B L I O GR A P H IE DE L O U ISE D UPRÉ 1
}

\author{
$+++$ \\ MÉLANIE BEAUCHEMIN ET NATHALIE WATTEYNE \\ Université de Sherbrooke
}

\section{E U V R E S}

\section{A. Pó ésie}

+ La peau familière, Montréal, Éditions du remue-ménage, 1983, 127 p.

+ Où, Montréal, Éditions de La Nouvelle Barre du jour, coll. «On voit plus de prodiges merveilleux \& de belles choses", 1984, 21 p.

+ Chambres, Montréal, Éditions du remue-ménage, coll. "Connivences», 1986, 93 p. (Réédition en format poche: Montréal, Éditions du remue-ménage, 1991, 92 p., et 1996, 90 p.)

+ "Quand on a une langue on peut aller à Rome», avec Normand de Bellefeuille, Montréal, Éditions de La Nouvelle Barre du jour, coll. «Auteur/e», 1986, 62 p. (Repris en cassette audio par Les productions A.M.A. enr., Laval, 1989.)

+ Bonheur, Montréal, Éditions du remue-ménage, coll. «Connivences», 1988, 103 p. (Extraits parus dans "Souffles», Nouveaux cahiers méditerranéens, $n^{\text {os }} 151-152,3^{\text {e }}$ et $4^{\text {e }}$ trimestres 1989 , p. 15-20.)

+ Noir déjà, Montréal, Éditions du Noroît, 1993, 94 p. (Extraits parus dans Estuaire, n 58, décembre 1990, p. 13-16; Possibles, vol. 16, n² 2, printemps 1992, p. 145-151.)

+ Tout près, Montréal, Éditions du Noroît, 1998, 95 p. (Extraits parus dans Tableaux, no 1 , automne 1998, p. 11; Danielle Shelton et Claudine Bertrand [dir.], La poésie prend le métro, Montréal, Éditions Adage, 2004, p. 27 ; Pierre Graveline [dir.], Les cent plus beaux poèmes québécois, Montréal, Fides, 2007, p. 72-73.)

+ Les mots secrets, Montréal, La Courte Échelle, coll. «Poésie», 2002, 39 p.

+ Une écharde sous ton ongle, Montréal, Éditions du Noroît, 2004, 100 p.

\section{B. Rom a n s}

+ La memoria, Montréal, XYZ éditeur, coll. «Romanichels», 1996, 219 p. (Réédition: Montréal, XYZ éditeur, coll. «Romanichels poche», 1997, 213 p. ; publié à Tournai (Belgique), La Renaissance du livre, 2002, 246 p.)

+ La Voie lactée, Montréal, XYZ éditeur, coll. «Romanichels», 2001, 199 p.

1 Nous remercions Louise Dupré de son aide précieuse. 


\section{Théêt r e}

+ Si Cendrillon pouvait mourir!, création collective, Montréal, Éditions du remue-ménage, 1980, 79 p.

+ Tout comme elle, suivi d'une conversation avec Brigitte Haentjens, Montréal, Québec Amérique, coll. «Mains libres», 2006, 110 p.

\section{Nouvelles}

+ L'été funambule: nouvelles, Montréal, XYZ éditeur, coll. «Romanichels», 2008, 156 p.

\section{E. Es s a is}

+ La théorie, un dimanche, avec Louky Bersianik, Nicole Brossard, Louise Cotnoir, Gail Scott et France Théoret, Montréal, Éditions du remue-ménage, 1988, 208 p.

+ Stratégies du vertige, trois poètes: Nicole Brossard, Madeleine Gagnon, France Théoret, Montréal, Éditions du remue-ménage, coll. «Itinéraires féministes», 1989, 265 p.

\section{F. Anthologies}

+ Montréal des écrivains: fiction, avec la collaboration de Bruno Roy et France Théoret (dir.), Montréal, l'Hexagone, coll. «Typo», 1988, 222 p.

+ Simone Routier, Comment vient l'amour, et autres poèmes, Montréal, Les Herbes rouges, coll. «Five o'clock», 2005, 155 p.

+ Nicole Brossard, D'aube et de civilisation, Montréal, Typo, 2008, 464 p.

\section{G. Livres d'art et textes surdes artistes visuels}

+ "Water's Stones», avec Eva Brandl, «Fictions/Installations», La Nouvelle Barre du jour, nos 189190, décembre 1986, p. 49-58.

+ «Sans titre» (avec le peintre Jean-Luc Herman), poème-affiche tiré à 20 exemplaires numérotés de 1 à 20, Paris, Éditions Jean-Luc Herman, 1994, $1 \mathrm{f}$.

+ Renoncement, suite poétique accompagnée de six peintures originales de Jean-Luc Herman, calligraphiée et signée, Paris, Éditions Jean-Luc Herman, 1995, 32 f.

+ «Lettres de souvenance de Chantal Dupont», texte accompagnant l'exposition de l'artiste Chantal Dupont au Salon des professeurs de l'UQAM, du 23 mars au 30 avril 1998, et publié dans le Spuq-info, n 192, avril 1998, p. 14.

+ Parfois les astres, avec Denise Desautels, conception de Jacques Fournier, Montréal, Éditions Roselin, 2000, $3 \mathrm{f}$.

+ "Vous êtes ici", Passion et tourment. La collection Luc LaRochelle, catalogue d'exposition sous la direction de Suzanne Pressé, Sherbrooke, Musée des beaux-arts de Sherbrooke, 2000, p. 24.

+ Le noir, la lumière, aux dépens de l'artiste, Ottawa, 2002, 20 f. Suite poétique avec des aquarelles originales signées Chan Ky-Yut, créations uniques pour chacun des trois exemplaires.

+ «Domesticités. À propos de photographies de Susan Mc Eachern », Mario Côté, François Lacasse et Sylvie Readman (dir.), Épreuves de distance, Montréal, Galerie de l'UQAM/Lux Éditeur, 2003, p. 47-57. [Avec un CD]

\section{H. Textes de création dans des périodiques et des anthologies \\ + «Défaites », La Nouvelle Barre du jour, nos 68-69, septembre 1978, p. 39-41. \\ + «La fête sans loup», La Nouvelle Barre du jour, nº 75, février 1979, p. 5-10.}


+ «Cognation», La Nouvelle Barre du jour, n 77, avril 1979, p. 75-80.

+ «La main posée autrement», La Nouvelle Barre du jour, nos 92-93, juin 1980, p. 121-127.

+ «Blanche mort», Calendrier 1982, Montréal, Éditions du remue-ménage, 1981, p. 2.

+ «Les désordres du privé», La Nouvelle Barre du jour, n 98, janvier 1981, p. 7-39.

+ «Programme double», La Nouvelle Barre du jour, n ${ }^{\text {os }}$ 100-101, mars 1981, p. 73-76.

+ "Lieux réversibles», La Nouvelle Barre du jour, no 112, mars 1982, p. 55-62.

+ "Complicités singulières", La Nouvelle Barre du jour, nos 122-123, février 1983, p. 110-114.

+ «Les désordres du privé», Canadian Women Studies/Les cahiers de la femme, vol. V, n 1 , automne 1983, p. 75.

+ «Temps mort», 1984. Poetry Agenda Poésie, Sainte-Anne de Bellevue, The Muses' Company, semaine du 3 au 9 septembre 1984.

+ "Anamorphose», Lèvres urbaines, n 6, $1^{\mathrm{er}}$ trimestre 1984, p. 6; Montréal est une ville de poèmes vous savez, anthologie préparée par Claude Beausoleil, Montréal, l'Hexagone, 1992, p. 215.

+ «Suite nomade $1 »$, Arcade, nº 7, mai 1984, p. 5.

+ «Exit», La Nouvelle Barre du jour, n 140, juin 1984, p. 61.

+ «Portrait», Passages, n 3, printemps-été 1984, p. 41-42.

+ «Portrait», Montreal Now!, 2e trimestre 1984, p. 5.

+ «Elle se serait penchée à la fenêtre», "Poésie 1984 », Estuaire, nºs 32-33, été-automne 1984, p. 61-63.

+ «Machination» et «Neuf textes», La Nouvelle Barre du jour, n 156, 1985, p. 35-39.

+ "Hypothèse » et «Les Québécois", Doc(k)s, n 66, hiver 1985, p. 114-115.

+ «Suite nomade», Passages, nº 6, printemps-été 1985, p. 9-14.

+ «Quand on a une langue...», avec Dominique Fugère, La Nouvelle Barre du jour, nº 163, novembre 1985, p. 51-54.

+ «Temps mort» et "Les désordres du privé», Judith Fitzgerald (dir.), SP/ELLES, Poetry by Canadian Women/Poésie de femmes canadiennes, Toronto, Black Moss Press, 1986, p. 41-47.

+ «Intrigue, distraite», Passages, no 8, hiver 1986, p. 7-11.

+ «Langue baroque», Travers, nos 27-28, juin 1986, p. 18.

+ «Sur le mur noir...», Urgences, n 15, octobre 1986, p. 24.

+ "Sans titre», Le Québec en poésie, anthologie préparée par Jean Royer, Paris, Gallimard/Lacombe, coll. «Folio Junior», 1987, p. 119. (Second tirage en 1995.)

+ «Rocaille d'octobre», avec Normand de Bellefeuille, Urgences, n 16, mars 1987, p. 34-35.

+ «Lettre retrouvée», Estuaire, no 45, été 1987, p. 35-37.

+ "Des dizaines, des centaines de fois...», XYZ. La revue de la nouvelle, nº 11, automne 1987, p. 36.

+ «Tourist Room», Maison de la poésie, nos 2-3, janvier 1988, p. 45-48.

+ «Tranquillité», Arcade, n 15, février 1988, p. 45-48.

+ "Gravité», Estuaire, n 50, automne 1988, p. 46-47.

+ «Évidence», Osiris, no 27, décembre 1988, p. 33-37.

+ «Vacarme», Matières, n 17, printemps 1989, p. 50-52.

+ "Liszt ou Schumann", La Nouvelle Barre du jour, nos 218-219, avril 1989, p. 29-38.

+ "Juillet», XYZ. La revue de la nouvelle, nº 18, mai-été 1989, p. 15-18.

+ «À pareille heure», Trois, vol. V, $n^{\text {os }} 1-2$, automne 1989, p. 126-127.

+ "L'intervalle», XYZ. La revue de la nouvelle, n²2, mai-été 1990, p. 26-28.

+ «Le chat», Maison de la poésie, n 8, novembre 1990, p. 61-65. 
+ «Instantanés», Trois, vol. VI, nos 2-3, hiver-printemps 1991, p. 168-169.

+ «[Extraits des recueils La peau familière, Où, Chambres et Bonheur] », Nicole Brossard et Lisette Girouard (dir.), Anthologie de la poésie des femmes au Québec, Montréal, Éditions du remueménage, 1991, p. 250-252.

+ «Histoire de poupée», Mœbius, nº 47, hiver 1991, p. 93-96.

+ "Chambre 28», XYZ. La revue de la nouvelle, no 28, hiver 1991, p. 31.

+ «Insomnies», Arcade, n 21, printemps 1991, p. 77-81.

+ «Trois poèmes», Le Sabord, n² 28, printemps-été 1991, p. 29.

+ "Poèmes", Regart, no 14, octobre 1991.

+ «La ville quelquefois», Estuaire, nos 65-66, automne 1992, p. 100-102.

+ «Les yeux gelés», Arcade, no 25, automne 1992, p. 41-42.

+ «Instantanés», Ritmica, no 8, juin 1992, p. 81-82.

+ "Ailleurs, New York », André Carpentier et Matt Cohen (dir.), Voix parallèles/Parallel Voices, Montréal/Kingston, XYZ éditeur/Quarry Press, 1993, p. 51-57.

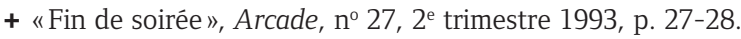

+ «Mémoire creuse», Tessera, vol. XIV, été 1993, p. 27-36.

+ "Certains novembres», Westcoast Line, n 12, hiver 1993-1994, p. 59-60.

+ "Au centre du visage», Osiris, no 38, 1994, p. 34-39.

+ «L'étoile», Arcade, no 31, 4 e trimestre 1994, p. 27-28.

+ «Sans titre», L'Arbre à paroles, n 80, mai-juin 1994, p. 74.

+ "Trou de silence», Bernard Magnier (dir.), La parole nomade, Montréal, Hurtubise/HMH, coll. «Collection Plus», 1995, p. 70.

+ «Sans titre», L'Arbre à paroles, n 83, janvier-février 1995, p. 62.

+ «Rivages en flammes», Le Moule à gaufres, no 14, janvier 1996, p. 58-60.

+ "Tranquillité», Arcade, nos 35-36, $1^{\text {er }}$ trimestre 1996, p. 82-83.

+ «Poèmes», Le Sabord, nº 42, hiver 1996, p. 15.

+ «Les mots désuets», XYZ. La revue de la nouvelle, n 48, hiver 1996, p. 14-17.

+ «Fragments de nuit», Trois, vol. XI, nos 1-2, mai 1996, p. 222-223.

+ «Une main ouverte», Autour du temps, Anthologie de poètes québécois, Montréal, Éditions du Noroît, 1997, p. 21-25. [Accompagné d'un CD.]

+ «Sourire», Trois, vol. XII, n 2, 2e trimestre 1997, p. 203.

+ «Petits éclats», Le Sabord, printemps-été 1997, p. 8.

+ "Tous les jardins, tous les parcs», XYZ. La revue de la nouvelle, no 50, été 1997, p. 58-65.

+ «Sans témoin", Les Écrits, no 90, août 1997, p. 13-18.

+ «Un peu de langue», Estuaire, n 88, septembre 1997, p. 73-74.

+ «Passage», Mœbius, n 78, automne 1998, p. 101.

+ «Fenêtres», Action poétique, nos 153-154, hiver 1998-printemps 1999, p. 122-126.

+ «Le monde vidé», Vwa, nº 62, hiver 1998-1999, p. 17-23.

+ "Voix off ", Joseph Bonenfant, Alain Horic et France Théoret (dir.), Les grands poèmes de la poésie québécoise, Montréal, l'Hexagone, 1999, p. 307-311.

+ "[Extraits des recueils Bonheur, Noir déjà et Tout près] ", Richard Giguère, Philip Lanthier et André Marquis (dir.), Anthologie de la poésie des Cantons de l'Est au 20e siècle, Montréal, Triptyque/Véhicule Press, 1999, p. 202-205.

+ "Petites espérances », Claudine Bertrand et Patricia Latour (dir.), Etres femmes, Pantin/TroisRivières, Le temps des cerises/Les Écrits des Forges, 1999, p. 58-61. 
+ «Désert», Sylvie Bergeron (dir.), Pierres et lierres, Sherbrooke, Éditions GGC, 1999, p. 37-38.

+ «Le retour», Arcade, n 45, printemps 1999, p. 41-44.

+ "Poème, liberté», Europe, no 839, mars 1999, p. 222-223.

+ «La robe noire», XYZ. La revue de la nouvelle, n 58, été 1999, p. 12-15.

+ «La petite fille», dans "Québec Lieux d'échange», Lynn Diamond (dir.), Lieux d'être, n 28 , été 1999, p. 53-55.

+ «Marées», Midi, no 8, automne 1999, p. 62-63.

+ «Vertige», Estuaire, n 98, automne 1999, p. 52-56.

+ «Paysages », Claudine Bertrand (dir.), Le Québec des poètes, Montréal, Trait d'union, 2000, p. 125-127.

+ «La vie rêvée», Simone Sauren (dir.), La maison du rêve, Montréal, l'Hexagone, 2000, p. 73-76.

+ "Tout est possible», "L'amour est un don", "Telle une amante» et "Encore une fois je croirai», Denise Joyal et Hélène Thibaux (dir.), Poèmes d'amour, Montréal, Éditions du Noroît, 2001, p. 87, 120, 127 et 137 .

+ «Les mains des gisants», Coup de soleil, n 52, juin 2001, p. 15-17.

+ «Rêverie», Mœebius, no 90, été 2001, p. 97-99.

+ "Le dé à coudre», Un lac, un fjord, un fleuve. Jardins secrets, n 8, septembre 2001, p. 99-102.

+ «Une fois encore», La France des poètes, Montréal, Trait d'Union, 2002, p. 81-83.

+ «Chaque pas», Jet d'encre, n 2, automne 2002, p. 13-15.

+ «Feuillaisons», Bacchanales, n 29, novembre 2002, p. 20-21.

+ «Louise Dupré», Alvaro Faleiros (dir.), Poètes du Noroît. Petite anthologie de la poésie québécoise, Montréal, Bibliothèque québécoise, 2003, p. 59-65.

+ «Un rire», XYZ. La revue de la nouvelle, n 76, hiver 2003, p. 42-46.

+ «Le dernier octobre», Arcade, no 62, automne 2004, p. 38-40.

+ "Accompagnement», Estuaire, no 120, septembre 2004, p. 50-54.

+ "Sans témoin", dans "Anthologie (1954-2004)», André Brochu (dir.), Les Écrits, numéro spécial, septembre 2004, p. 325-328.

+ «La vie humble», Le Tiroir de l'imajuscule, printemps 2005, p. 40.

+ «Octobre», Poésie contemporaine des deux rives, n 3, novembre 2005, p. 169-176.

+ «L'aube», L'année en poésie 2007. Calendrier de la poésie francophone: anthologie, Berthem, Alhambra Publishing, 2006.

+ «Un rire», Siècle 21. Littérature et société, no 9, automne-hiver 2006, p. 33-35.

+ "Vertige», Jacques Allard (dir.), Le bonheur des poètes, Trois-Rivières/Montréal, Écrits des Forges/Productions Virage, 2007, p. 69-70.

+ "Là-haut», L'année en poésie 2007. Calendrier de la poésie francophone 2008, Berthem, Alhambra Publishing, 2006.

+ «Louise Dupré», John Ennis, Randall Maggs et Stephanie McKenzie (dir.), The Echoing Years. An Anthology of Poetry from Canada \& Ireland, Waterford, Center for Newfoundland and Labrador Studies, School of Humanities and Waterford Institute of Technology, 2007, p. 201204.

+ «Louise Dupré», Laurent Mailhot et Pierre Nepveu (dir.), La poésie québécoise. Des origines à nos jours, Montréal, Typo, 2007, p. 578-581.

+ "Tu m'as légué», «Il suffit de si peu», "Chaque poème est un automne», «Les os exacts», L'Arbre à paroles, n 139, printemps 2008, p. 22-25. 


\section{Articles dans des collectifs, périodiques ou journaux}

+ «L'urgence d'une critique féministe», Le Devoir, 28 avril 1979, p. 26.

+ "Slingshot de France Vézina», Livres et auteurs québécois 1979, Québec, Les Presses de l'Université Laval, 1980, p. 178-179.

+ «Figure de grève», Voix et Images, vol. V, nº 3, printemps 1980, p. 597-598.

+ «Des textes qui témoignent», Spirale, nº 11, septembre 1980, p. 9.

+ «La spirale amoureuse», Spirale, $n^{\circ} 13$, novembre 1980, p. 7.

+ "Gémellaires. Le chemin de Damas de Suzanne Jacob et Passeport blasphématoire pour l'hiver québécois de Francine Péotti», Livres et auteurs québécois 1980, Québec, Les Presses de l'Université Laval, 1981, p. 109-111.

+ «Rester seule», L'agenda des Éditions du remue-ménage 1982, Montréal, Éditions du remueménage, 1981.

+ "L'écriture féminine dans Les Herbes rouges », La Revue de l'Université d'Ottawa, vol. L, nº 1, 1981, p. 89-94.

+ «L'avortement et le pouvoir», Spirale, n 17 , mars 1981, p. 11.

+ «La dame de cœur», Spirale, n 22, février 1982, p. 13.

+ «Innocence ou naïveté ?", Spirale, no 24, avril 1982, p. 9.

+ «Un texte nomade», Spirale, n 24, avril 1982, p. 9.

+ «La mémoire longue», Spirale, n 25, mai 1982, p. 4.

+ «Toujours future», Spirale, n 26, juin 1982, p. 7.

+ «Du corps et de l'effet», Spirale, n² 27, septembre 1982, p. 16.

+ «Fragments d'urgences», «La mère peut-elle être moderne?», La Nouvelle Barre du jour, no 116, septembre 1982, p. 57-63.

+ "Quand les hommes lisent les femmes», Spirale, n 29, novembre 1982, p. 11.

+ «Les utopies du réel», «Traces, écriture de Nicole Brossard», La Nouvelle Barre du jour, nos 118119, novembre 1982, p. 83-89.

+ «Deux accents de mémoire», Spirale, no 39, décembre 1982, p. 11.

+ «Une écriture de l'orage», Spirale, n 31, février 1983, p. 71.

+ «Le roman de la bonne conscience», Spirale, n 33, avril 1983, p. 6.

+ «Savoir la désobéissance», Spirale, no 34, mai 1983, p. 7.

+ «De la chair à la langue. Poésie et féminisme», La Vie en rose, no 11, mai 1983, p. 54-55.

+ «La vigilance d'abord!», Spirale, n 36 , septembre 1983, p. 8.

+ «Où loge le Noroît?", Spirale, no 37, octobre 1983, p. 8.

+ "Quelques réflexions civiles», "Intellectuel/le en 1984? », La Nouvelle Barre du jour, nos 130131, octobre 1983, p. 135-149.

+ «La croyance en question», Spirale, n 38 , novembre 1983, p. 14.

+ «La mise à nu», Spirale, n 40, février 1984, p. 23.

+ «Le féminisme rose de Rose Sélavy» (entrevue avec Marie-Madeleine Raoult et Yolande Villemaire), La Vie en rose, n 17 , mai 1984, p. 56-57.

+ «Étrangement, la nouvelle écriture... », La Nouvelle Barre du jour, n 141, septembre 1984, p. 50-51.

+ "Question de maîtrise», Arcade, n 8, octobre 1984, p. 48-51.

+ «BJ/NBJ : pour une lecture des politiques éditoriales», Voix et Images, vol. X, n 2, hiver 1985 , p. 115-124.

+ «Qui parle?», Estuaire, nº 38, hiver 1985-1986, p. 41-47. 
+ «Réflexions sur la poésie», Choisir la poésie, Trois-Rivières, Écrits des Forges, 1986, p. 71-73.

+ «Star Words», La Nouvelle Barre du jour, n 172, mars 1986, p. 79-84.

+ «Valoriser la lecture», Cegepropos, n 103, novembre 1986, p. 4.

+ «La traversée des miroirs», avec Louise Cotnoir, La Nouvelle Barre du jour, nº 196, mars 1987, p. 19-25.

+ «Du geste à la voix», Trois, vol. III, n² 2, hiver 1987-1988, p. 65-66.

+ «Pour une théorie du scandale», Estuaire, n 47, hiver 1987-1988, p. 35-41.

+ «Du propre au figuré» (préface), Nicole Brossard, L'Amèr, Montréal, l'Hexagone, coll. «Typo», 1988, p. 7-13.

+ "Au noir de l'écriture/On the Dark Side of Write», Contemporary Verse II, vol. XI, nºs 2-3, printemps-été 1988, p. 66-75.

+ "Critique littéraire: une enquête», Spirale, nº 81, septembre 1988, p. 6.

+ "Une conscience posthistorique», "Dialogue Conversation/Une écriture à deux», Tessera, vol. V, septembre 1988, p. 35-36.

+ «Pour contrer l'ère du vide», Trois, vol. IV, nº 1, automne 1988, p. 88-89.

+ «Une poésie de l'effraction», Voix et Images, vol. XIV, n 1, automne 1988, p. 24-30.

+ «Portrait de l'artiste, revu et corrigé», La Revue des Écrits des Forges, n²6, novembre 1988, p. 77-82.

+ «De l'interdit à l'inédit», La Nouvelle Barre du jour, ns 214-215, novembre 1988, p. 85-95.

+ «Entre autres villes, Montréal», Lire Montréal, Les Presses de l'Université de Montréal, 1989, p. 73-84.

+ "Quand la nouvelle poésie devient amoureuse», Trois, vol. IV, n² 2, hiver 1989, p. 19-24.

+ «Une généalogie de la perte», La Nouvelle Barre du jour, nos 216-217, janvier 1989, p. 6580.

+ "Geste de Anne-Marie Alonzo ", Spirale, n 90, septembre 1989, p. 9.

+ «La traversée des générations», Trois, vol. V, nos 1-2, automne 1989, p. 245-246.

+ "La béance entre les scènes", "Vers une narratologie féministe/Toward Feminist Narratology", Tessera, vol. VII, automne 1989, p. 34-38.

+ «Une pensée vivante», Claire Lejeune (dir.), Les Cahiers internationaux de symbolisme, nos 65 66-67, 1990, p. 21-27.

+ «L'amour: cette autre identité», Voix et Images, vol. XV, nº 2, hiver 1990, p. 298-301.

+ «Un livre: effets d'une machine», Urgences, n 28, mai 1990, p. 41-47.

+ «Montréal en poésie», Yannick Gasquy-Resch (dir.), Marseille-Montréal. Centres culturels cosmopolites, Paris, L'Harmattan, 1991, p. 181-193.

+ «Rire ou pleurer? ?, Voix et Images, vol XVI, n 2, hiver 1991, p. 340-344.

+ "Écrire dans les murs», Mœbius, no 50, automne 1991, p. 11-28.

+ «Le tremblement de la conscience. Entretien avec Louky Bersianik», Voix et Images, vol. XVII, no 1, automne 1991, p. 11-21.

+ "Poésie, rébellion, subversion», Marguerite Andersen et Christine Klein-Lataud (dir.), Paroles rebelles, Montréal, Éditions du remue-ménage, 1992, p. 279-295. (Repris dans Lori SaintMartin (dir.), L'autre lecture, tome II, Montréal, XYZ éditeur, 1994, p. 149-160.)

+ "La critique-femme. Esquisse d'un parcours», Annette Hayward et Agnès Whitfield (dir.), Critique et littérature québécoise, Montréal, Triptyque, 1992, p. 397-406.

+ "Une traversée des territoires", Simon Harel (dir.), L'étranger dans tous ses états. Enjeux culturels et littéraires, Montréal, XYZ éditeur, 1992, p. 53-60. 
+ «La critique au féminin : réalité et utopie», Claudine Potvin et Janice Williamson (dir.), Women's Writing and the Literary Institution/L'écriture au féminin et l'institution littéraire, Edmonton, University of Alberta, Reseach Institute for Comparative Literature, 1992, p. 69-77. + "Au cœur du silence», Le Sabord, no 31, printemps-été 1992, p. 31.

+ «La prose métisse du poème. Sur Anne-Marie Alonzo », Québec Studies, n 15, automne 1992hiver 1993, p. 51-56.

+ «De la lettre au poème: la correspondance Gaston Miron-Claude Haeffely », études réunies et présentées par Benoît Melançon et Pierre Popovic, Les facultés des lettres. Recherches récentes sur l'épistolaire français et québécois, Montréal, Centre universitaire pour la sociopoétique de l'épistolaire et des correspondances, 1993, p. 229-241.

+ «La peau tragique des déchirures», Yolande Grisé, Réjean Robidoux et Paul Wyczynski (dir.), Émile Nelligan. Cinquante ans après sa mort, Saint-Laurent, Fides, 1993, p. 229-235.

+ «La critique au féminin», Claude Duchet et Stéphane Vachon (dir.), La recherche littéraire. Objets et méthodes, Paris/Montréal, Les Presses de l'Université de Vincennes/XYZ éditeur, 1993, p. 379-386.

+ «Denise Desautels: La pensée du poème», Études françaises, nºs 29-30, hiver 1993, p. 41-50.

+ "Anatomie d'un personnage: la folle d'Elvis », Voix et Images, vol. XVIII, n 3, printemps 1993, p. 553-563.

+ «Un texte, deux voix» (postface), Anne-Marie-Alonzo et Denise Desautels (dir.), Lettres à Cassandre, Laval, Éditions Trois, 1994, p. 107-119.

+ «Bloody Mary et autres recueils de poésie de France Théoret», Gilles Dorion (dir.), Dictionnaire des œuvres littéraires du Québec (1976-1980), tome VI, Saint-Laurent, Fides, 1994, p. 88-90.

+ «Écrire comme vivre: dans l'hybridité. Entretien avec Anne-Marie Alonzo», Voix et Images, vol. XIX, n² 2, hiver 1994, p. 238-250.

+ «Écriture et enfermement», Simon Harel (dir.), Antonin Artaud. Figures et portraits vertigineux, Montréal, XYZ éditeur, 1995, p. 135-143.

+ «La poésie en prose au féminin : jeux et enjeux énonciatifs», Recherches sémiotiques/Semiotic Inquiry, Barbara Havercroft (dir.), vol. XV, nº 3, 1995, p. 9-24.

+ «Lucie Bourassa. Rythme et sens. Des processus rythmiques en poésie contemporaine», Recherches sémiotiques/Semiotic Inquiry, vol. XV, n 3, 1995, p. 193-198.

+ «Un savoir-vivre», Trois, vol. 10, n² 2, hiver 1995, p. 184-186.

+ "Louise Cotnoir: le romanesque de la poésie en prose», dans «Écritures au féminin. Le genre marqué», Lori Saint-Martin (dir.), Tangence, nº 47, mars 1995, p. 34-42.

+ "Alonzo, Anne-Marie», Christiane P. Makward et Madeleine Cottenet-Hage (dir.), Dictionnaire littéraire des femmes de langue française. De Marie de France à Marie Ndiaye, Paris, Karthala, 1996, p. 23-25.

+ «Claudine Bertrand: Le feu sacré», Lettres québécoises, n 81, printemps 1996, p. 18-19.

+ "Quelques notes sur la critique-femme», Tangence, no 51, mai 1996, p. 144-156.

+ "Le lièvre de mars de Louise Warren. Vers une réalité "virtuelle" ", Voix et Images, vol. XXII, $\mathrm{n}^{\circ} 1$, automne 1996, p. 67-77.

+ «La qualité totale», Spirale, no 150, septembre-octobre 1996, p. 5.

+ «Cela, oui, le poème», dans «De l'écriture du poème», Jean Duval (dir.), Estuaire, n 89, novembre 1997, p. 93-101.

+ «Racines poétiques, racines maternelles», Revue des lettres et de traduction (Université SaintEsprit, Kaslik, Liban), nº 4, 1998, p. 117-128. 
+ «Là d'où je viens. Notes sur l'écriture et le féminisme», Trois, vol. XIII, nº 2, février 1998, p. 41-50.

+ «L'an 2000, ici, maintenant», dans «Le futur à l'essai», Claudine Bertrand (dir.), Arcade, nº 43, mai 1998, p. 41-50.

+ «Un visage appuyé contre le monde de Hélène Dorion. Une esthétique de la perte», Lucie Joubert (dir.), Trajectoires au féminin dans la littérature québécoise, Québec, Nota bene, 1999, p. 19-33.

+ «Je voudrais commencer cette réflexion... », Yvon Montoya et Pierre Thibeault (dir.), Frénétiques. Treize intellectuels québécois répondent à la question: Quelle est votre perception de la culture au Québec à l'aube du XxI siècle?, Montréal, Triptyque, 1999, p. 43-48.

+ "Christine Palmiéri. Une vertigineuse verticalité», Vie des Arts, nº 174, printemps 1999, p. 4143.

+ «Apprendre la vie. Sur Apprendre à vivre de Hugues Corriveau», Lettres québécoises, n 93 , printemps 1999, p. 13-14.

+ «Briser le miroir», Lettres québécoises, n 95, automne 1999, p. 7.

+ «Une affaire de plumeau», Voix et Images, vol. XXV, nº 1, automne 1999, p. 27-29.

+ "Une culture commune? Se plaire ou se plaindre», Spirale, n 168, septembre-octobre 1999, p. 7.

+ «Le geste d'écrire», Les Écrits, n 97, décembre 1999, p. 139-144.

+ "L'imaginaire au féminin dans la littérature québécoise », Monique Pontault (dir.), Femmes en francophonie, Paris, L’Harmattan, coll. «Cahiers de la francophonie», 2000, p. 149-154.

+ «La fragilité de vivre» (préface), Jacques Brault, Poèmes (1963-1980), Montréal, Éditions du Noroît, 2000, p. 7-19.

+ "Quelques esquisses, de mémoire», Paul Chamberland, Michaël Lachance, Georges Leroux et Pierre Ouellet (dir.), Mélanges offerts en hommage à Michel van Schendel, Montréal, l'Hexagone, 2001, p. 443-447.

+ «Déplier le temps. Mémoire et temporalité dans La promeneuse et l'oiseau et Ce fauve, le Bonheur de Denise Desautels», Voix et Images, vol. XXVI, n² 2, hiver 2001, p. 302-316.

+ «D'abord l'intime. Entretien avec Denise Desautels», Voix et Images, vol. XXVI, n 2, hiver 2001, p. 227-240.

+ «Présentation», Voix et Images, vol. XXVI, n 2, hiver 2001, p. 225-226 [dossier Denise Desautels].

+ «Une écriture de la passion», Lettres québécoises, n 101, printemps 2001, p. 12.

+ "Mémoire et écriture. L'inscription du féminin dans l'histoire», Miléna Santoro (dir.), Québec Studies, vol. 31, printemps-été 2001, p. 24-35.

+ «Introduction» (avec Jaap Lintvelt et Janet Paterson), Jaap Lintvelt, Janet Paterson et Louise Dupré (dir.), Sexuation, espace, écriture. La littérature québécoise en transformation, Québec, Nota bene, 2002, p. 7-21.

+ "Entre raison et déraison de France Théoret. Esquisse d'une cartographie de l'écriture», Jaap Lintvelt, Janet Paterson et Louise Dupré (dir.), Sexuation, espace, écriture. La littérature québécoise en transformation, Québec, Nota bene, 2002, p. 25-41.

+ «Le mot de l'Académie. Douceur», Le Devoir, 15 juillet 2002, p. A1-2.

+ "L'éblouissement du réel», Liberté, n 253, septembre 2002, p. 67-71.

+ «Carnets de la survie», Liberté, n 258, novembre 2002, p. 32-43.

+ "Écriture et sexuation: l'identité en question», 14 novembre 2002, sur le site Internet de la Société royale du Canada. < www.rsc.ca/files/publications/presentations/2002/dupre.pdf >. 
+ "Dérive : à partir de Regards et jeux dans l'espace», Paul Bélanger (dir.), Saint-Denys Garneau. La clef de la lumière, Montréal, Éditions du Noroît, 2003, p. 99-105.

+ "Le roman des frontières», Carmen Boustani (dir.), Aux frontières des deux genres, Paris, Éditions Kartala, 2003, p. 131-143.

+ «Écrire au féminin: de la théorie à la pratique», Cincinnati Romance Review, vol. XXIII, mai 2004, p. 10-31.

+ «Écrire d'une main blessée», Les Écrits, n 111, août 2004, p. 21-35.

+ «La vie: comme rien d'autre. À propos du texte de Denise Desautels, En état d'urgence», Mœbius, $\mathrm{n}^{\circ}$ 104, hiver 2005, p. 7-10.

+ «Que faisons-nous?», Spirale, n 200, janvier-février 2005, p. 16-17.

+ «Sujet féminin, sujet lyrique», Nathalie Watteyne (dir.), Lyrisme et énonciation lyrique, Québec/ Bordeaux, Éditions Nota bene/Les Presses Universitaires de Bordeaux, 2006, p. 185-206.

+ "Rhétorique et effets de féminin. Je t'écrirai encore demain de Geneviève Amyot», Annette Hayward (dir.), La rhétorique au féminin, Québec, Éditions Nota bene, 2006, p. 461-478.

+ «Signature Duras», Danielle Laurin (dir.), Lettres à Marguerite Duras, Montréal, Éditions Varia, 2006, p. 72-77.

+ "Cinquante femmes bien vivantes: la magie du théâtre", L'agenda des femmes 2007, Montréal, Éditions du remue-ménage, 2006.

+ «Ā partir d'un fait divers», Mœbius, nº 110, automne 2006, p. 11-15.

+ "Le sujet autobiographique comme sujet poétique. Le deuil du soleil de Madeleine Gagnon», Robert Dion, Frances Fortier, Barbara Havercroft et Hans-Jürgen Lüsebrink (dir.), Vies en récit. Formes littéraires et médiatiques de la biographie et de l'autobiographie, Québec, Éditions Nota bene, coll. «Convergences», 2007, p. 247-264.

+ «Espaces de la mémoire, espaces du féminin. Langues obscures de Nicole Brossard», Jeanette den Toonder (dir.), avec la collaboration de Hilligje van't Land, Les voix du temps et de l'espace, Éditions Nota bene, coll. «Convergences», 2007, p. 347-363.

+ «L'atelier de poésie», Vincent Charles Lambert (dir.), Leçons du poème, Québec, Éditions Nota bene, coll. "Cahiers du Centre Hector-De-Saint-Denys-Garneau», n² 2, 2008, p. 23-26.

+ «Un pur bonheur», Stéphane Lépine (dir.), Sibyllines. Un parcours pluriel, Montréal, Les 400 coups, 2008, p. 100-103.

\section{J . S cénario de fil m}

+ À part des autres, Marcel Simard (réal.), textes de Louise Dupré, Claude Cartier, Marcel Simard, Emmanuelle Turgeon, Martin Ouellet, Montréal, ONF/Productions Virage inc., 2005, 100 min, $55 \mathrm{sec}$.

\section{K. Entretiens}

+ RICARD, François, Louise DUPRÉ et Jean-Marcel PAQUETTE, «Critique littéraire : une enquête", Spirale, no 81, septembre 1988, p. 6-8.

+ MOLIN-VASSEUR, Annie, "Entretien avec Louise Dupré», Arcade, no 32, hiver 1995, p. 57-68.

+ MARTEL, Réginald, «La mémoire de Louise Dupré», La Presse, 24 novembre 1997, p. B-8.

+ ROY, Monique, «Écrire l'amour: un écrivain se raconte», Châtelaine, vol. XLII, n 11 , novembre 2001, p. 90-91.

+ AMYOT, Linda, «Louise Dupré. Questionner l'existence», Nuit blanche, n 93, hiver 2003-2004, p. 24-28. 
+ TUNARU, Otilia, «Interview avec Louise Dupré», Terra Nova Magazine, n² 24, août 2006, www.terranovamagazine.ca.

+ FORTIN, Julien, «Paroles. Entretien avec Louise Dupré», L'Écrit primal, no 38, 2e trimestre 2008, p. 35-44.

\section{EEUVRS PARUES EN TRADUCTION}

\section{A. Romans et poésie}

+ Memoria, traduction anglaise de Liedewy Hawke, Toronto, Simon \& Pierre, 1999, 207 p.

+ The Milky Way, traduction anglaise de Liedewy Hawke, Toronto, Simon \& Pierre, 2002, 207 p.

+ The Blueness of Light. Selected Poems, 1988-2002, traduction anglaise de Antonio D'Alfonso, Toronto, Guernica, 2005, 71 p.

\section{B. Textes de création dans des périodiques et des anthologies}

+ «Chambres (Extraits)», traduction anglaise de Judith Cowan, Matrix. New Canadian Writing, n 26, printemps 1988, p. 26-29.

+ «Gravity», traduction anglaise de Lucille Nelson, Lip, vol. II, n 4, mars 1989, p. 14-17.

+ «Liszt or Schumann», traduction anglaise de Judith Cowan, Lou Robinson et Camille Norton (dir.), Resurgent, Urbana/Chicago, University of Illinois Press, 1992, p. 74-81.

+ «Sans titre», traduction espagnole, «Poetas del Quebec», Feminaria, n 9, Ano V, novembre 1992, p. 15.

+ «Elsewhere, New York», traduction anglaise de Ann Diamond, André Carpentier et Matt Cohen (dir.), Voix parallèles/Parallel Voices, Montréal/Kingston, XYZ éditeur/Quarry Press, 1993, p. 57-62.

+ «Tierra de sombra», traduction espagnole de Monica Mansour, «Semanal», La Jornada, n 283, 13 novembre 1994, p. 41-42.

+ «Bevroren Lippen », traduction néerlandaise de Marianne Gossije, Conny Steenman-Marcusse (dir.), Vonken van vrijheid, Breda, Uitgeverij de Geus, 1995, p. 195-201.

+ "De "Au fond de la lumière"/From "The Depths of Light" (Extraits)», traduction anglaise de Lou Nelson, The Review, n 3, été 1997, p. 46-49.

+ «Renoncement», traduction anglaise de Hugh Hazelton et traduction espagnole de Roberto Jovel, Ruptures, n 13, octobre 1997-mars 1998, p. 70-78.

+ «Doprodov» et «Ptaci Klec», traduction tchèque de Jana Boxbergerova, Tvar, décembre 1998, p. 6-7.

+ «Louise Dupré», traduction en chinois de Cheng Yirong, Cheng Yirong (dir.), La poésie québécoise, Hong Kong, Quaille, 2000, p. 133-136.

+ "De "Au fond de la lumière" /From "In the Depths of Light" (Extraits)», traduction anglaise de Lou Nelson, The Review, n 6, printemps 2000, p. 42-45.

+ «Rien »/« Nothing», traduction anglaise de Patrick Williamson, La Traductière, n 19, juin 2001, p. 30-31.

+ «Tout près (Extraits)», traduction brésilienne de Alvaro Faleiros, Alvaro Faleiros (dir.), 9 poètes du Québec/9 poetas do Quebec, Montréal/Sao Paulo, Éditions du Noroît/Nankin Editorial, 2002, p. 90-99.

+ «Milécna Draha» (La Voie lactée), traduction tchèque de Peter Vurm, Eva Le Grand et Gaëtan Lévesque (dir.), Hledani Ameriky. Antologie soucasneho quebeckého romanu (1980-2000), Prague/Montréal, Host/XYZ éditeur, 2003, p. 213-227. 
+ «Todos los jardines, todos los parques» («Tous les jardins, tous les parcs»), traduction espagnole de Félix Cortés Schöler, Gaëtan Lévesque (dir.), Dias de Quebec. Antologia de cuentos del Quebec contemporano, Mexico, Conaculta Fonca, 2003, p. 117-124.

+ «Na zglobu obzorja», traduction slovène de Barbara Pogacnik, dans «Quebeska Poezija 20 stoletja», Literatura, nos 148-149, octobre-novembre 2003, p. 154-157.

+ «Untitled», traduction anglaise de David Solway, David Solway, Demilunes. Little Windows on Québec, Victoria, Frog Hollow Press, 2005, p. 36.

+ «Voice over", traduction anglaise de Antonio D’Alfonso, Exile, vol. XXIX, nº 1, printemps 2005, p. 89-100.

+ «Deux poèmes de "Mai" », traduction anglaise de Antonio D'Alfonso, Ellipse, n 75, automne 2005, p. 32-35.

+ «Passage», traduction anglaise de Elaine Lewis, dans «Sculpture sur prose», La Traductière, $\mathrm{n}^{\circ} 25$, juin 2007, p. 51.

+ «Poesie di Louise Dupré», traduction italienne de Viviane Ciampi, Fili d'aquilone. Rivista d'immagini, idee et Poesia, no 8, octobre-décembre 2007, www.filidaquilone.it.

\section{Articles}

+ «La mémoire complice doublement/The Doubly Complicit Memory», traduction anglaise de Kathy Mezei et Daphne Marlatt, Room of One's Own, vol. VIII, n 4, 1984, p. 25-40.

+ "From Experimentation to Experience. Quebecois Modernity in the Feminine», traduction anglaise de A. S. Holden Verburg, A Mazing Space. Writing Canadian/Women Writing, Shirley Neuman et Smaro Kamboureli (dir.), Edmonton, Longspoon Press/Newest Press, 1986, p. 355-360.

+ «Poetry Returns to Love», traduction anglaise d'Arlette Francière, Ellipse, n 39, automne 1988, p. 11-19.

+ «Writing. The Hand», traduction anglaise de Robert Majzels, Matrix. New Canadian Writing, $\mathrm{n}^{\circ}$ 50, automne 1997, p. 78-79.

+ «Desdobrar o tempo. Memoria e temporalidade em La promeneuse et l'oiseau e Ce fauve, le Bonheur de Denise Desautels", traduction brésilienne de Patricia Chittoni Ramos, Nubia Jacques Hanciau, Eliane T. A. Campello et Eloina Prati dos Santos (dir.), A voz da critica canadense no feminino, Rio Grande, Editora da furg, 2001, p. 79-102.

+ «Women's Writing in Quebec. From Rhetoric to New Social Propositions», traduction anglaise de Michelle Carolyn Tracy et Conny Steenman-Marcusse (dir.), The Rhetoric of Canadian Writing, Amsterdam/New York, Rodopi, 2002, p. 21-36.

+ «Novels on the Edge», traduction de Louise H. Forsyth, Louise H. Forsyth (dir.), Nicole Brossard. Essays on Her Works, Toronto, Guernica, 2005, p. 84-100.

\section{Traductions en français par Louise Dupré}

+ «Chevelure» (traduction de «Head of Hair» de Ann Diamond), dans André Carpentier et Matt Cohen (dir.), Voix parallèles/Parallel Voices, Montréal/Kingston, XYZ éditeur/Quarry Press, 1993, p. 176-183.

+ «Je suis capable» (traduction de «I am able» de Simon Armitage), La Traductière, n 16 , juin 1998, p. 8.

+ «Vieillards» (traduction de «Old Men» de Eva Bourke), La Traductière, n 16, juin 1998, p. 10.

+ «Chanson sans paroles» (traduction de «Song without Words» de Susan Glickman), La Traductière, nº 16, juin 1998, p. 16. 
+ «Palinodie», «In lumen insania» et «Pas et passim» (traduction de «Palinodia», «In lumen insania» et «Pas et passim»), Daniele Pieroni, Orazioni, Rome, Casta Diva, 2006, p. 97-99.

\section{DIRECTION D'OUVRAGES ET DOSSIERS DE REVUES}

+ "À quelques obsessions près», Hugues Corriveau, Louise Cotnoir et Louise Dupré (dir.), La Nouvelle Barre du jour, n 77, avril 1979, 87 p.

+ «Intellectuel/le en 1984 ?", Normand de Bellefeuille et Louise Dupré (dir.), La Nouvelle Barre du jour, nos 130-131, octobre 1983, 149 p.

+ «Bruits et silences», Louise Dupré (dir.), Arcade, no 21, printemps 1991, 128 p.

+ «Louky Bersianik», Louise Dupré (dir.), Voix et Images, vol. XVII, nº 1, automne 1991, 157 p.

+ Dans l'écriture, André Carpentier, Paul Chamberland, Louise Dupré et René Lapierre (dir.), Montréal, XYZ éditeur, coll. "Travaux de l'atelier», 1994, 113 p.

+ Le travail de la forme, André Carpentier, Paul Chamberland, Louise Dupré et René Lapierre (dir.), Montréal, XYZ éditeur, coll. «Travaux de l'atelier», 1995, 101 p.

+ «La pensée s'invente», Bianca Côté, Louise Dupré, France Mongeau et Germaine Mornard (dir.), Arcade, no 32, printemps 1995, 81 p.

+ «Traduire la poésie», Louise Dupré (dir.), Trois, vol. XV, nos 1,2 et 3, 1999, p. 147-180.

+ «Denise Desautels», Louise Dupré (dir.), Voix et Images, vol. XXVI, n 2, hiver 2001, p. 225335.

+ Sexuation, espace, écriture. La littérature québécoise en transformation, Louise Dupré, Jaap Lintvelt et Janet M. Paterson (dir.), Québec, Nota bene, coll. «Littérature (s)», 2002, 487 p.

+ L'atelier de l'écrivain I, Denise Brassard, André Carpentier, Paul Chamberland, Louise Dupré et René Lapierre (dir.), Montréal, Centre de recherche sur le texte et l'imaginaire, coll. «Figura», 2004, 196 p.

\section{V. PRIX ET DISTINCTIONS}

+ Prix Alfred-DesRochers 1984, pour La peau familière.

+ Finaliste au Prix du Gouverneur général 1986, pour Chambres.

+ Finaliste au Grand Prix du Festival international de poésie de Trois-Rivières 1987, pour Chambres.

+ Finaliste au Prix du Gouverneur général 1989, pour Bonheur.

+ Grand Prix du Festival international de poésie de Trois-Rivières 1993, pour Noir déjā.

+ Prix de la Société des écrivains canadiens (section de Montréal) 1996, pour La memoria.

+ Prix Ringuet de l'Académie des lettres du Québec 1997, pour La memoria.

+ Deuxième Grand Prix de poésie Radio-Canada 1997, pour Tout près.

+ Finaliste au Prix France-Québec (Jean Hamelin) 2001, pour La Voie lactée.

+ Finaliste au Grand Prix du Festival international de la poésie de Trois-Rivières 2004, pour Une écharde sous ton ongle.

+ Finaliste au Prix du Gouverneur général 2004, pour Une écharde sous ton ongle.

+ Prix de la critique pour la saison 2005-2006 (catégorie Montréal) par l'Association québécoise des critiques de théâtre (AQCT), 2006, pour le spectacle Tout comme elle. 


\section{RÉCEPTION CRITIQUE ET PRINCIPALES ÉTUDES}

\section{A. Monographie}

+ JÉZÉQUEL, Anne-Marie, Louise Dupré: Le Québec au féminin, avant-propos de Karen L. Gould, Paris, L’Harmattan, coll. «Critiques littéraires», 2008, 270 p.

\section{B. Ét u d e s}

+ LAMY, Suzanne, «Des enfants uniques, nés de père et de mère inconnus», Quand je lis je m'invente, Montréal, l'Hexagone, 1984, p. 29-43.

+ MCPHERSON, Karen, "The Future of Memory in Louise Dupré's La Memoria», Paula Ruth Gilbert, Roseanna L. Dufault (dir.), Doing Gender. Franco-Canadian Women Writers of the 1990's, Madison, NJ/London, England, Fairleigh Dickinson UP/Asssociated UP, 2001, p. 142159.

+ MCPHERSON, Karen, "Memory Works», Archaeologies of an Uncertain Future. Recent Generations of Canadian Women Writing, Montreal/Kingston, McGill/Queen's University Press, 2006, p. 58-77.

+ MOSS, Jane, "Québec Women's Drama and The New Generation", Québec Studies, nº 40, automne-hiver 2006, p. 111-125.

+ POPKIN, Debra, «Quebec novelist Louise Dupré, La memoria and La Voie lactée, Starting over, a Second Chance at Happiness », Bettina R. Lerner and Juan Carlos Mercado (dir.), A Living Legacy. CCNY Department of Foreign Languages and Literatures Undergraduate Alumni Conference (May 5-6, 2006), Newark (Delaware), Juan de la Cuesta Publisher, 2007, p. 131141.

+ WATTEYNE, Nathalie, «Voix d'outre-tombe dans les poèmes en prose d'Isabelle Pinçon et de Louise Dupré», Michaël Brophy et Mary Gallagher (dir.), Sens et présence du sujet poétique, Amsterdam, Rodopi, coll. «Faux titre», 2006, p. 339-346.

\section{Portraits}

+ ARCHAMBAULT, Gilles, «Savoir lire», Le Devoir, 17 novembre 2006, p. A-1.

+ BORDELEAU, France, Hugues CORRIVEAU, «Louise Dupré: le vertige de l'écriture, absolument», Lettres québécoises, n 95, automne 1999, p. 7-13.

+ CAMPION, Blandine, «Louise Dupré: Beauté et résurrection. Entre poésie et roman, être en mouvement dans la vie», Le Devoir, 22 novembre 1997, p. D-7.

+ CORBO, Linda, «La lauréate Louise Dupré, poète de l'intimité», Le Nouvelliste, 4 octobre 1993, p. 4.

+ DIJKGRAAF, Margot, «Poëzie is beter dan geloof», NRC Handelsblad, 16 avril 1999, p. 34.

+ LAMONTAGNE, Marie-Andrée, "Louise Dupré, Une écharde sous ton ongle», Liber bulletin, avril 2006, p. 5 .

+ VENNAT, Pierre, «La pensée s'invente», La Presse, 30 avril 1995, p. B-7.

\section{Comptes rendus et articles de presse}

1. Póésie

\section{a) La peau familière}

+ ALONZO, Anne-Marie, "Poésie vibrante», La Vie en rose, n 14, novembre-décembre 1983, p. 60.

+ BAYARD, Caroline, «Peau - savoir cruel», Lettres québécoises, n³2, hiver 1983-1984, p. 3435. 
+ BEAUSOLEIL, Claude, «Les mots familiers», Le Devoir, 17 septembre 1983, p. 19 et 22.

+ GRISÉ, Yolande, «Le sentiment très vif d’une urgence», Spirale, n 39, décembre 1983, p. 4.

+ LÉPINE, Stéphane, «La peau familière», Nos livres, vol. XIV, octobre 1983, p. 20-21.

+ MALENFANT, Paul Chanel, "La peau familière», Nuit blanche, nº 11, décembre 1983janvier 1984, p. 12.

\section{b ) $O$ ù}

+ ROYER, Jean, «De l'érotisme avant toute chose», Le Devoir, 9 mars 1985, p. 24.

\section{c) Chambres}

+ ALONZO, Anne-Marie, "Chambres», Estuaire, no 43, hiver 1986-1987, p. 75-76.

+ ALONZO, Anne-Marie, "Chambres», La Vie en rose, février 1987, p. 52.

+ BROCHU, André, «L'interrogation totale de la mort», Voix et Images, vol. 13, n 1, automne 1987, p. 165-174.

+ CHAMBERLAND, Roger, "Chambres de Louise Dupré», Québec français, n 65, mars 1987, p. 14.

+ FOURNIER, Danielle, "Chambres», Arcade, n 13, février 1987, p. 84-85.

+ GAUDET, Gérald, «L'écho des chambres», Trois, vol. II, n² 2, hiver 1987, p. 51-52.

+ GONZAGUE, Louise de, "Chambres», Nos livres, vol. XVIII, ns 6795-6827, janvier 1987, p. 31.

+ MARQUIS, André, "La répétition de l'intime», Lettres québécoises, n 45, printemps 1987, p. $44-46$.

+ MOORHEAD, Andrea, "Chambres», The French Review, vol. LXIII, n 3, février 1990, p. 579.

+ NAUDIN, Marie, «Poésie-manifeste», Littérature canadienne, n 120, juillet 1989, p. 218-220.

+ NEPVEU, Pierre, «Tourist Room», Spirale, n 69, avril 1987, p. 7.

+ ROYER, Jean, «Deux récits de l'intelligence et du cœur», Le Devoir, 3 janvier 1987, p. C-4.

+ TURCOTTE, Suzy, «Chambres», Nuit blanche, n 27, mars-avril 1987, p. 18.

\section{d) "Quand on a une langue, on peut aller à Rome"}

+ BAYARD, Caroline, «Le récit à la nb», Lettres québécoises, n 46, été 1987, p. 34-35.

+ ROYER, Jean, «Le sentiment de la langue», Le Devoir, 28 février 1987, p. C-3.

\section{e) Bonheur}

+ BROCHU, André, «La critique est faillible», Voix et Images, vol. XIV, n 3, printemps 1989, p. 513-521.

+ CORRIVEAU, Hugues, «L'intimité de l'écriture», Trois, vol. IV, nº 3, printemps-été 1989, p. 120 121.

+ DÉRY-MOCHON, Jacqueline, "Voix de peine modulée en bonheur», Trois, vol. IV, n 3 , printemps-été 1989, p. 122.

+ LATENDRESSE, Claude, "La mémoire des liens», Estuaire, n 55, hiver 1990, p. 76-78.

+ MARQUIS, André, «Apprivoiser le bonheur», Lettres québécoises, n 54, été 1989, p. 33-34.

+ POPOVIC, Pierre, "Partir, revenir, voyager, écrire peut-être...", Spirale, n 85, février 1989, p. 5.

\section{f ) Noir déjà}

+ AUDET, Jacques, «Noir déjà », Lecture, vol. I, nº 2, octobre 1993, p. 12-13. 
+ BERTRAND, Claudine, «Imaginaire érotique et souveraineté du désir dans l'écriture des femmes au Québec», Ruptures, no 9, avril-septembre 1995, p. 255-260.

+ BOUCHER, France, «Dupré, Louise, Noir déjà », La poésie au Québec (revue critique) 1993, Trois-Rivières, Écrits des Forges, 1996, p. 43-44.

+ CLOUTIER, Guy, «Noir déjà », Le Soleil, 7 juin 1993, p. B-5.

+ DUMONT, François, «Dans la nuit abstraite», Le Devoir, 8-9 mai 1993, p. D-4.

+ FELX, Jocelyne, «La note juste», Lettres québécoises, n 71, automne 1993, p. 43-44.

+ JACQUOT, Martine, «Noir déjà », Envol, vol. II, no 3, été 1994, p. 38-40.

+ LAURIN, Danielle, «Je sème à tout vent», Voir (Cahier spécial livres), vol. VII, n 50, 11-17 novembre 1993, p. 24.

+ LIBERT, Béatrice, «Louise Dupré. Noir déjā», L'Arbre à paroles, n 96, automne 1997, p. 81.

+ TOUPIN, Gilles, «Des poèmes pour la terre et pour Margie Gillis», La Presse, 23 mai 1993, p. B-6.

\section{g) Tout près}

+ BISSONNETTE, Thierry, "Les marcheurs, Nicole Richard. Tout près, Louise Dupré», Nuit blanche, $\mathrm{n}^{\circ}$ 74, printemps 1999, p. 36.

+ CANTIN, David, «Les trajets incontournables», Le Devoir, $16-17$ janvier 1999, p. D-3.

+ CORRIVEAU, Hugues, "Poème, oui, puisqu'il faut s'égarer», Lettres québécoises, n 74, été 1999, p. 43.

+ NEPVEU, Pierre, «Du côté de la vie, malgré tout», Spirale, mai-juin 1999, p. 16.

\section{h) Les mots secrets}

+ CANTIN, David, «Dis-moi qui je suis», Le Devoir, 16-17 mars 2002, p. D-2.

+ CHAREST, Rémy, "Premiers poèmes", Le Soleil, 21 mars 2002, p. B-1-2.

+ DESROCHERS, Gisèle, "Jeunesse de la poésie», Le Devoir, 9-10 février 2002, p. D-1-2.

+ LESSARD, Valérie, "Quand poésie rime avec adolescence», Le Droit, 16 mars 2002, p. A-4.

+ SARFATI, Sonia, «La poésie dès l'adolescence», La Presse, 21 mars 2002, p. C-2.

\section{i) Une écharde sous ton ongle}

+ BOUCHER, France, «Tel un hurlement», Arcade, n 62, automne 2004, p. 98-99.

+ CANTIN, David, «Le double silencieux du poète», Le Devoir, 12-13 juin 2004, p. F-4.

+ DESPATIE, Stéphane, "Quatre saisons dans le désordre», Voir, 20-26 mai 2004, p. 28.

+ FELX, Jocelyne, «Pour traverser la nuit», Lettres québécoises, nº 116, hiver 2004, p. 37.

\section{Rom a n s}

\section{a) La memoria}

+ ALLARD, Jacques, «Comment revient l'amour», Le Devoir, 25-26 mai 1996, p. D-3. [Repris dans Le roman mauve, Montréal, Québec Amérique, 1997, p. 366-370.]

+ ARCHER, Bert, «Dupré's fiction translates into success», Now, 29 avril-5 mai 1999.

+ BARTLEY, Jim, "Memoria, by Louise Dupré», The Globe and Mail, 29 mai 1999, p. D-11.

+ BOIVIN, Aurélien, «La memoria ou l'art de réapprendre l'amour et la vie», Québec français, no 118, été 2000, p. 89-91.

+ CAMPION, Blandine, «D'amour et de littérature», Le Devoir, 18-19 avril 1998, p. D-6.

+ HOWLETT, Debbie, «Double dose of what the heart remembers», The Gazette, 7 août 1999, p. 13. 
+ MARCOTTE, Gilles, «Lettre à ma cousine», L'Actualité, août 1996, p. 77.

+ MARTEL, Réginald, «Louise Dupré. Un premier roman lumineux et grave», La Presse, 31 avril 1996, p. B-3.

+ NAVARRO, Pascale, «Les beaux souvenirs», Voir, 9-15 mai 1996, p. 33

+ POULIN, Andrée, "Louise Dupré nous entraîne au cœur des larmes. La mémoire de la douleur», Le Droit, 18 mai 1996, p. A-11.

+ SILVERMAN, Marjorie, "Memoria », Independantly Reviewed, vol. II, n² 2, hiver 2000-2001.

+ VOISARD, Anne-Marie, «La poésie du bonheur», Le Soleil, $1^{\mathrm{er}}$ juin 1996, p. D-9.

\section{b) La Voie lactée}

+ CHARTRAND, Robert, "Portraits de femmes à modeler», Le Devoir, 21-22 avril 2001, p. D-4.

+ FOURNIER, Danielle, «La parole amoureuse», Spirale, n 186, octobre 2002, p. 56-57.

+ HAHN, Cynthia T., «Dupré Louise. La Voie lactée», Études francophones, vol. XVI, nº 2 , automne 2001, p. 176-181.

+ LACHANCE, Lise, «Louise Dupré. Aucun délai de livraison», Le Soleil, 23 juin 2001, p. D-9.

+ MARCOTTE, Gilles, «Écritures à risques», L'Actualité, 1 1er juin 2001, p. 91-92.

+ MARTEL, Réginald, «Une œuvre bien sage», La Presse, 8 avril 2001, p. B-4.

+ NAVARRO, Pascale, "Raison et sentiments», Voir, 22-28 mars 2001, p. 38.

+ SODERSTROM, Mary, "The Milky Way», Quill \& Quire, juin 2002, p. 48.

+ THIBAULT, Dominique, "La Voie lactée», Québec français, n 123, automne 2001, p. 20-21.

+ WOODS, Thomas S., "New love, old ghosts», The Globe and Mail, 11 août 2002, p. D15.

\section{T h é ât r e}

\section{a) Si Cendrillon pouvait mourir! (création collective)}

+ MOSS, Jane, «Feminist Theatre in Quebec», Canadian Literature, n 132, printemps 1992, p. 167-169.

\section{b) Tout comme elle}

+ CHENELIÈRE, Evelyne de la, «Tout comme elle. L'expérience féminissime, (Journal rédigé rétrospectivement mais somme toute assez fidèle je crois)", Les Cahiers du théâtre français, septembre 2006, p. 6-7.

+ CORRIVEAU, Hugues, «Tout comme le corps parle», Lettres québécoises, no 122, été 2006, p. 34-35.

+ CRÉPEAU, Jean-François, «Tout comme elle. Un croisement de monologues», Canada français, 25 janvier 2006, p. C-6.

+ CYR, Catherine, «Mater Dolorosa», Jeu, no 120, 3 e trimestre 2006, p. 19-23.

+ DUMAS, Ėve, "Théâtre/Tout comme elle, Cinquante mères et filles», La Presse, 14 janvier 2006, p. AS-15.

+ FORTIN, Marie-Claude, «La rentrée d'hiver. De la littérature avant toute chose», La Presse, 15 janvier 2006, p. AS-11.

+ GAUTHIER, Natasha, «Inside the blood ties that bind women - Dupre's new play on motherdaughter relationships hits close to home», The Ottawa Citizen, 31 octobre 2006, p. D-7.

+ GUAY, Hervé, «Telle mère, telle fille?», Le Devoir, 21 janvier 2006, p. C-6.

+ LABRECQUE, Marie, "Du mystère amoureux au nœud douloureux », Le Devoir, 14 janvier 2006, p. E-1, E-2. 
+ LAURIN, Danielle, «Ma mère, ma fille et moi», Châtelaine, février 2006, p. 26-27.

+ LÉPINE, Stéphane, Un chœur qui bat, Montréal, Publications Sibyllines, 2006, 36 p. [Entretiens de Louise Dupré et de Brigitte Haentjens.]

+ L'HÉRAULT, Pierre, «Le battement des mots», Spirale, n 209, juillet-août 2006, p. 53-54.

+ MARCOTTE, Gilles, «Vers le sud, pour perdre le nord», L'Actualité, 15 septembre 2006, p. 9192.

+ POULIOT, Sophie, «Théâtre. Ma mère, mon miroir », Elle Québec, janvier 2006, p. 28.

+ SAINT-PIERRE, Christian, «Brigitte Haentjens et Louise Dupré. De mères en filles», Voir, 12-18 janvier 2006, p. 34.

+ ST-HILAIRE, Jean, «Avant-première de Tout comme elle, Cinquante comédiennes viennent en aide au Carrefour international de théâtre de Québec», Le Soleil, 17 mars 2006, p. B-4.

+ TANGUAY, Antoine, «Louise Dupré. Tout comme elle», Le Soleil, 19 février 2006, p. C-4.

\section{Nouvelles}

\section{a) L'été funambule}

+ BÉRUBÉ, Jade, «Femmes en plein cœur de l'été», La Presse, 4 mai 2008, p. 7.

+ LAURIN, Danielle, «Écrire avec son âme», Le Devoir, 29-30 mars 2008, p. F-3.

+ MALAVOY-RACINE, Tristan, «Le tout pour le tout», Voir, 17 avril 2008, p. 16.

+ PEPIN, Elsa, «Peau de chagrin», Ici, 10 au 16 avril 2008, p. 48.

\section{Es s a is}

\section{a) La théorie, un dimanche}

+ BOIVIN, Jean-Roch, «Ceci n'est pas une critique et la théorie a ses limites», Le Devoir, 25 juin 1988, p. D-3.

+ CAMPEAU, Francine, "Le choix de La Parole métèque», La Parole métèque, nº 7, automne 1988, p. 38.

+ FORTIN, Marie-Claude, «Post Scriptum», Voir, 7-13 juillet 1988, p. 12.

+ FOURNIER, Danielle, "La théorie, un dimanche», Urgences, n 21, novembre 1988, p. 106-108.

+ PICARD, Anne-Marie, "La théorie, un dimanche», University of Toronto Quarterly, vol. 59, nº 1 , automne 1989, p. 206-209.

+ SIMON, Sherry, «La théorie, un dimanche», Spirale, nº 81, septembre 1988, p. 8.

+ THÉRY, Chantal, «C'est dans la fiction que se joue le devenir du féminisme comme philosophie», Lettres québécoises, n 51, automne 1988, p. 49-50.

\section{b) Stratégies du vertige}

+ BONENFANT, Joseph, «L'emprise de trois poésies», Voix et Images, vol. XV, n 2, hiver 1990, p. 282-286.

+ BROCHU, André, «Les belles solitudes», Voix et Images, vol. XV, n 2, hiver 1990, p. 282-286.

+ DESJARDINS, Louise, "Stratégies du vertige», Cahiers internationaux de symbolisme, nos 65-6667, 1990, p. 215-217.

+ GODARD, Barbara, "Lucid Paradox», Canadian Literature, été 1992, p. 190-191.

+ GOULD, Karen, «Stratégies du vertige», Quebec Studies, n 10, printemps-été 1990, p. 169-170.

+ PELLETIER, Benoît, «Un essai éclairant sur trois écritures au féminin », Le Devoir, 8 juillet 1989, p. C-7.

+ SAINT-MARTIN, Lori, «Entre le féminin», Spirale, no 91, octobre 1989, p. 3. 
+ WHITFIELD, Agnès, «Les écritures au féminin», Lettres québécoises, nº 56, hiver 1989-1990, p. $40-41$.

c) Sexuation, espace, écriture (avec Jaap Lintvelt et Janet $M$. Paterson)

+ MAVRIKAKIS, Catherine, [Compte rendu du livre], Voix et Images, vol. XXX, no 1 , automne 2004, p. 139-147.

d) "Entre autres villes, Montréal" (Lire Montréal)

+ BOIVIN, Jean-Roch, «Montréal vaut bien une courtepointe», Le Devoir, 12 août 1989, p. C-5.

\section{e) Le forum des femmes (numéro de La Nouvelle Barre $d u$ jour) ${ }^{2}$}

+ BAYARD, Caroline, "Le Forum des Femmes. La Nouvelle Barre du jour en amont de la pensée théorique au Québec», Lettres québécoises, nº 42, été 1986, p. 71-72.

f) "Poésie, rébellion, subversion" (Paroles rebelles)

+ DESJARLAIS-HEYNNEMAN, Mireille, «Pour connaître l'histoire qu'on ne nous a jamais apprise. Paroles rebelles ", L'Express, semaine du 20 au 26 octobre 1992.

g) "Un texte, deux voix" (Lettres à Cassandre)

+ GONZAGUE-PELLETIER, Louise de, "Anne-Marie Alonzo, Denise Desautels, Lettres à Cassandre, Postface de Louise Dupré», Envol, vol. III, nos 1 et 2, 1995, p. 72-73.

\section{h) The Blueness of Light ${ }^{3}$}

+ QUERENGESSER, Neil, «Diverse Explorations», Canadian Literature, n 193, été 2007, p. 129131.

\section{E. Mémoires et $t$ hè ses}

+ HÖLZL, Ingrid, «Die neue Prosaliteratur von Frauen in Québec. La memoria von Louise Dupré», mémoire de maîtrise, Innsbruck, Université d'Innsbruck, 2001, 99 f.

+ LAFLAMME, Elsa, «Parcours de l'intime dans la poésie en prose. La peau familière, Bonheur et Tout près de Louise Dupré», mémoire de maîtrise, Montréal, Université du Québec à Montréal, 2001, $129 \mathrm{f}$.

+ ARSENAULT, Jolyane, "L'amant étranger dans le roman québécois au féminin (1980-2004)», mémoire de maîtrise, Sherbrooke, Université de Sherbrooke, 2006, 120 f.

+ JÉZÉQUEL, Anne-Marie, "Louise Dupré. Les espaces de l'écriture», thèse de doctorat, Cincinnati, University of Cincinati, 2006, $270 \mathrm{f}$.

+ KARAM, Marie-Rose, "L'effet personnage dans le roman québécois d'Anne Hébert et de Louise Dupré», mémoire de maîtrise, Beyrouth, Université libanaise, 2007, 199 f.

2 Ce titre et les deux suivants sont des ouvrages qui contiennent un ou plusieurs textes de Louise Dupré. 3 Ce titre est la traduction d'un recueil de poèmes choisis de Louise Dupré. 


\section{F. Enregistrements vidéo}

+ MASSE, Jean-Pierre, SANTORO, Miléna (réal.) La théorie, un dimanche. Sweet: Suite (table ronde tenue par le groupe «La théorie, un dimanche» lors du colloque de l'American Council for Québec Studies (ACQS) à Montréal, en octobre 2000), Montréal, l'American Council for Québec Studies/Production Le conifère têtu inc., 2002, 85 min.

+ MAROTTE, Sylvain, Au fil des mots. Louise Dupré, poète, Danielle Thériault et Chantal Bowen (réal.), La Prairie, Téridan (Édition panoramique), 2005, 25 min.

+ MASSE, Jean-Pierre (réal.), Vivante. Louise Dupré, Production Le conifère têtu inc., 2005, $51 \mathrm{~min}$.

+ MASSE, Jean-Pierre (réal.), Tout comme elle, texte pour le théâtre de Louise Dupré, adaptation et mise en scène de Brigitte Haentjens, Montréal, Production Le conifère têtu inc., 2006, 79 min. 


\section{B IB LIOGR A P H IE DE LOUISE DUPRÉ TABLE DES MATIÈRES}

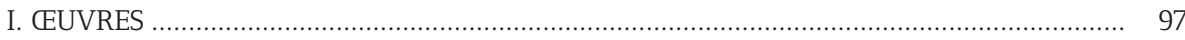

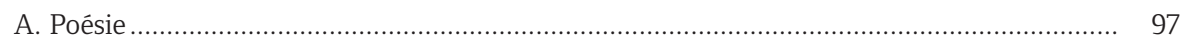

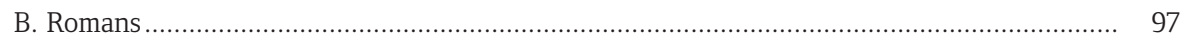

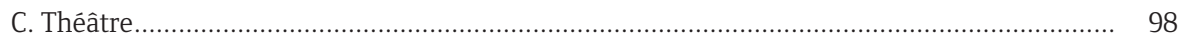

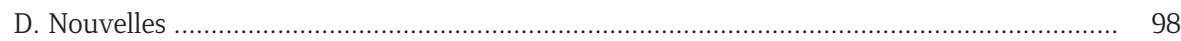

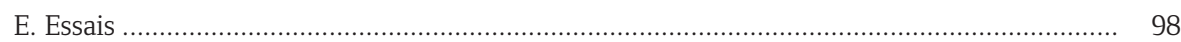

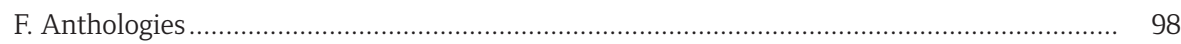

G. Livres d'art et textes sur des artistes visuels ............................................................. 98

$\mathrm{H}$. Textes de création dans des périodiques et des anthologies ............................................. 98

I. Articles dans des collectifs, périodiques ou journaux ...................................................... 102

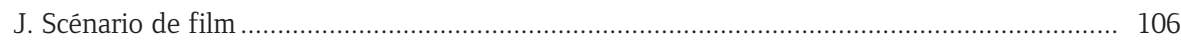

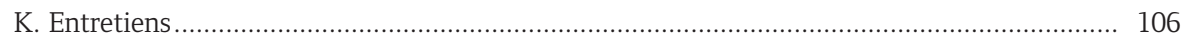

II. EUVRES PARUES EN TRADUCTION ……..................................................................... 107

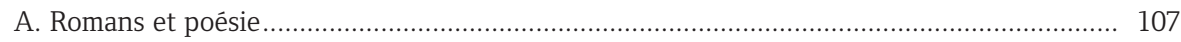

B. Textes de création dans des périodiques et des anthologies............................................ 107

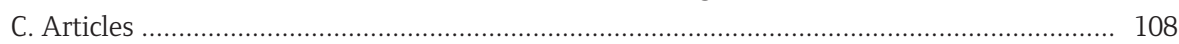

D. Traductions en français par Louise Dupré .................................................................... 108

III. DIRECTION D'OUVRAGES ET DOSSIERS DE REVUES ….................................................. 109

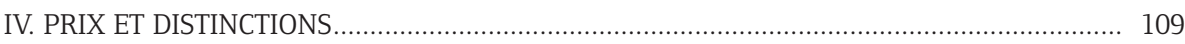

V. RÉCEPTION CRITIQUE ET PRINCIPALES ÉTUDES ............................................................ 110

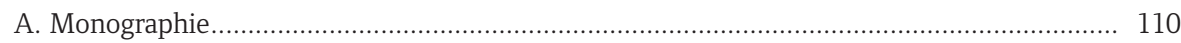

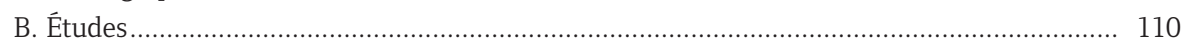

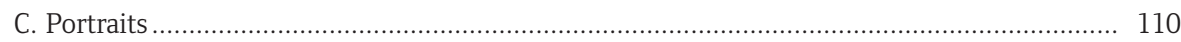

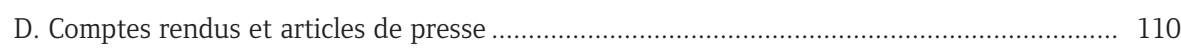

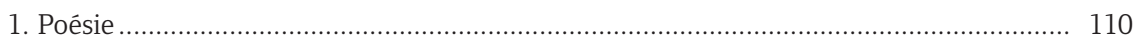

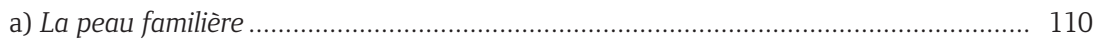

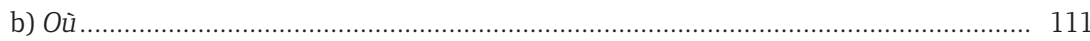

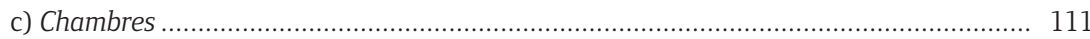

d) «Quand on a une langue, on peut aller à Rome» .................................................... 111

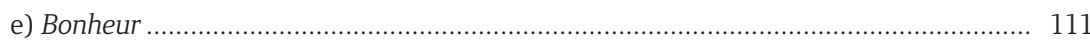

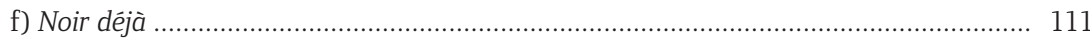

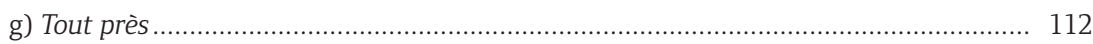

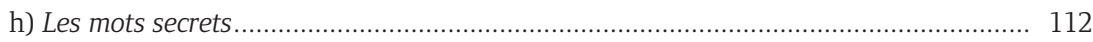

i) Une écharde sous ton ongle ................................................................................. 112

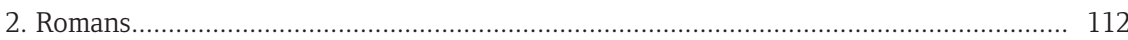

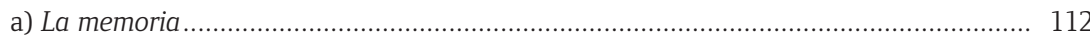

b) La Voie lactée ........................................................................................................ 113

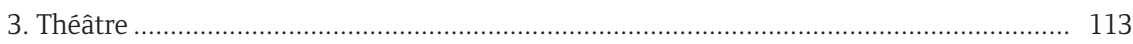

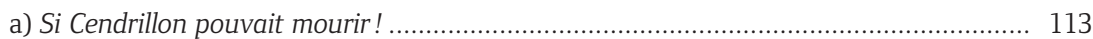

b) Tout comme elle .......................................................................................... 113

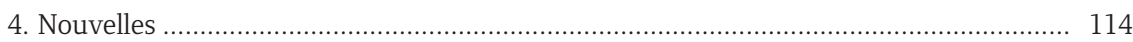

a) L'été funambule ............................................................................................. 114 


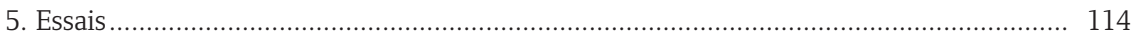

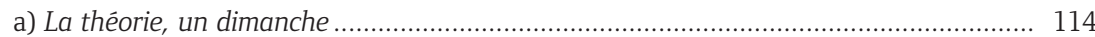

b) Stratégies du vertige ................................................................................... 114

c) Sexuation, espace, écriture ............................................................................... 115

d) «Entre autres villes, Montréal» (Lire Montréal) .................................................. 115

e) Le forum des femmes (numéro de La Nouvelle Barre du jour) ................................. 115

f) «Poésie, rébellion, subversion» (Paroles rebelles) ...................................................... 115

g) «Un texte, deux voix» (Lettres à Cassandre) ........................................................ 115

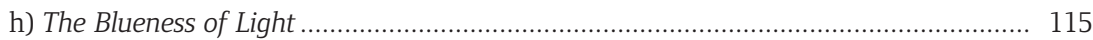

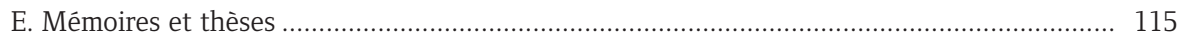

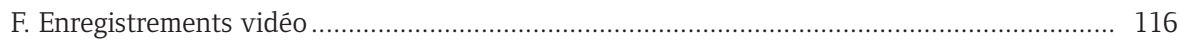

